(C) Elsevier Sequoia S.A., Lausanne - Printed in The Netherlands

\title{
POTENTIODYNAMIC CURRENT/POTENTIAL CHARACTERISTICS OF THEORETICAL MECHANISMS RELATED TO THE ELECTROCHEMICAL FORMATION AND ELECTROREDUCTION OF MONOLAYER FILMS ON INERT ELECTRODES
}

\author{
N.R. DE TACCONI, J.O. ZERBINO and A.J. ARVIA \\ Instituto de Investigaciones Físicoquimicas Teóricas y Aplicadas (INIFTA), División \\ Electroquímica, Casilla de Correo 16, Sucursal 4, La Plata (Argentina) \\ (Received 16th April 1976; in revised form 9th July 1976)
}

\begin{abstract}
The current/potential curves of various mechanisms related to the electrochemical formation and electroreduction of monolayer films on inert electrodes, involving a single surface covering species and two surface covering species are presented. The potential perturbation functions consist both of single either linear or triangular potential sweeps and of triangular modulated linear potential sweeps. A comparison of the theoretical $E / I$ displays obtained with the different potential perturbation techniques is given for the various reaction pathways presented.
\end{abstract}

\section{INTRODUCTION}

The use of potential pertubation methods is widespread in electrochemical research. Since the paper by Will and Knorr [1], the linear potential scan, either the single or the triangular technique, has received a great deal of attention as a simple and rapid method for obtaining information on electrode processes involving a submonolayer film at interfaces under a non-diffusion controlled kinetics. This method which was initially mostly applied as a qualitative tool, has proved also very useful to gain quantitative information [2-5]. The latter can be sometimes achieved when the perturbation conditions are adequately chosen through the potential/time profile acting on the interface reaction [6-9].

An interesting extension of the linear potential sweep technique consists of the triangular modulated linear potential sweep technique, developed by Conway et al. [10-12] which is being successfully applied to study hydrogen and oxygen submonolayer films on noble metal electrodes. This technique appears to be a powerful tool for studying reaction intermediates produced during the electrochemical reactions $[13,14]$.

In this paper some theoretical mechanisms which are considered of interest to understand the monolayer oxide electroformation and electrodissolution are presented. The corresponding theoretical $E / I$ profiles are calculated either for linear triangular potential sweeps of different potential amplitude or for a triangular modulated linear potential sweep. The influence of the different kinetic 
parameters of the individual steps and of the perturbation parameters on the shape of the $E / I$ profiles is described.

\section{(I) A SINGLE ELECTRON TRANSFER MECHANISM (SURFACE COVERAGE BY A SINGLE SPECIES)}

Let us first consider a single stage electrochemical reaction involving the electrooxidation of the anion $\mathrm{A}^{-}$on the metal $\mathrm{M}$ yielding a product $\mathrm{A}$ at the metal surface:

$\mathrm{M}+\mathrm{A}^{-} \rightleftharpoons \mathrm{M}(\mathrm{A})+e^{-}$

where any transport of matter towards or out of the metal/electrolyte interface, as well as electrical double layer charging or discharging processes are disregarded for the sake of simplicity. During a potentiodynamic scan the change of the surface coverage by species $(A)$ is given by equation:

$$
\begin{aligned}
& k(\mathrm{~d} \theta / \mathrm{d} t)=k_{1}(1-\theta) \exp [(1-\beta) E / b] \exp [-\alpha f(\theta)] \\
& -k_{-1} \theta \exp [-\beta E / b] \exp [(1-\alpha) f(\theta)]
\end{aligned}
$$

where $k_{1}$ and $k_{\sim 1}$ are the specific rate constants of reaction (I) in the anodic and cathodic direction, respectively, expressed in terms of the current density, $\beta$ is the symmetry factor related to the electron transfer barrier, $\alpha$ is a constant associated to the the change of the apparent adsorption free energy with surface coverage, the latter being expressed by $f(\theta)$, the corresponding standard state being referred to $\theta \rightarrow 0[15], k$ is the charge associated to the formation of a monolayer of A on the electrode, $E$ is the potential difference at the metal/ electrolyte interface and $b$ is the $R T / F$ ratio. Equation (1) can be expressed in terms of $E_{\mathrm{eq}}$, the standard reversible potential, as follows:

$$
\begin{aligned}
& k(\mathrm{~d} \theta / \mathrm{d} t)=K_{1}\left\{(1-\theta) \exp \left[(1-\beta)\left(E-E_{\mathrm{eq}}\right) / b\right] \exp [-\alpha f(\theta)]\right. \\
& \left.\quad-\theta \exp \left[-\beta\left(E-E_{\mathrm{eq}}\right) / b\right] \exp [(1-\alpha) f(\theta)]\right\}
\end{aligned}
$$

where:

$$
K_{1}=k_{1} \exp \left[(1-\beta) E_{\text {eq }} / b\right]=k_{-1} \exp \left[-\beta E_{\text {eq }} / b\right]
$$

$K_{1}$ is the exchange current density of reaction (I).

During the potential scan, the instantaneous current density, $i$, is obtained from the equation:

$i=k(\mathrm{~d} \theta / \mathrm{d} t)$

This differential equation is numerically solved for a triangular modulated single linear potential sweep, by using the 4th order Runge-Kutta integration method and the theoretical $E / I$ profiles are depicted on a IBM/2250 visual unit which is coupled to a IBM/360 computer using sets of possible kinetic parameters and perturbation potential conditions which can be experimentally approached.

In the following text the reversibility or irreversibility of the reaction is related to the ratio between the individual rate constants of the electrochemical process is both directions and the rate of potential perturbation applied to the system. Then in the following kinetic analysis one arbitrarily refers indifferently 
either to the degree of reversibility or the degree of irreversibility of the electrochemical system.

For a reversible process the $E / I$ display obtained with a triangular modulated linear potential sweep (t.m.l.p.s.) run from the initial potential $E_{\mathrm{i}}$, towards anodic potentials, corresponding to a particular set of $v_{\mathrm{g}}$, the guide potential rate, and $v_{s}$, the superimposed triangular potential sweep rate, is shown in Fig. 1. Both the anodic and cathodic $E / I$ contours are symmetrically placed with respect to $E_{\text {eq }}$ although the area pertaining to the anodic process is slightly larger than that related to the cathodic process, because for $v_{\mathrm{g}}=1.5 \mathrm{~V} \mathrm{~s}^{-1}$ and $v_{\mathrm{s}}=$ $20 \mathrm{~V} \mathrm{~s}^{-1}$, the actual potential sweep rate corresponding to the anodic and cathodic processes are, respectively, $21.5 \mathrm{~V} \mathrm{~s}^{-1}$ and $18.5 \mathrm{~V} \mathrm{~s}^{-1}$. The anodic area to cathodic area ratio, $A_{\mathfrak{a}} / A_{\mathrm{c}}$, approaches 1 when $v_{\mathrm{g}} \rightarrow 0$. The slopes of the lines connecting the points of the reversible anodic and cathodic $E / I$ contours at the inversion of the modulating signal, are practically equal to $90^{\circ}$. At each potential the veversible system attains instantaneously the equilibrium surface coverage degree and the contour of the modulated $E / I$ voltammogram then coincides with that displayed using a single linear potential sweep (s.l.p.s.) run at the same potential scan rate.

For a quasi-reversible process under a t.m.l.p.s. the overall $E / I$ display depicted in Fig. 2a presents an anodic and a cathodic contour. Now, the $E / I$ profiles corresponding to each modulating sweep exhibit maxima located respectively at the low left portion and at the upper right portion of the $E / I$ display, the corresponding currents being lower than those of the $E / I$ envelope. The cathodic portions of the modulated voltammograms agree with the $E / I$ displays (Fig. 2b) obtained with a single triangular potential sweep run from $E_{\mathrm{i}}$, within the same potential limits, since when the system reaches the null current conditions the same boundary conditions are valid for the integration of the corresponding differential equations. Either anodic or cathodic current peaks are observed during the individual modulating cycles when the rates of variation

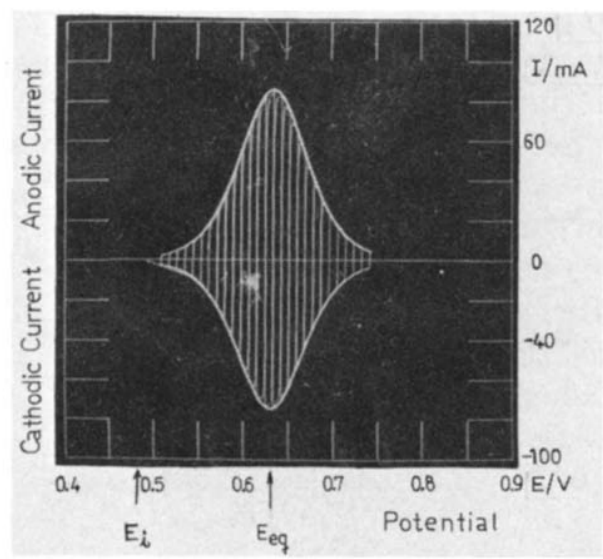

Fig. 1. Triangular modulated linear single potential sweep voltammogram calculated for mechanism (I) with the following parameters: $k_{1}=10^{-2} \mathrm{~mA} \mathrm{~cm} \mathrm{~cm}^{-2} ; k_{-1}=10^{9} \mathrm{~mA} \mathrm{~cm}{ }^{-2} ; \beta=$ $0.5, f(\theta)=0 ; k=0.4 \mathrm{mC} \mathrm{cm}-2 ; v_{\mathrm{g}}=1.5 \mathrm{~V} \mathrm{~s}^{-1} ; v_{\mathrm{s}}=20 \mathrm{~V} \mathrm{~s}^{-1} ; A_{\mathrm{s}}=0.06 \mathrm{~V} ; E_{\mathrm{eq}}=0.6325 \mathrm{~V}$; electrode area $=1 \mathrm{~cm}^{2} ; 290 \mathrm{~K}$. 


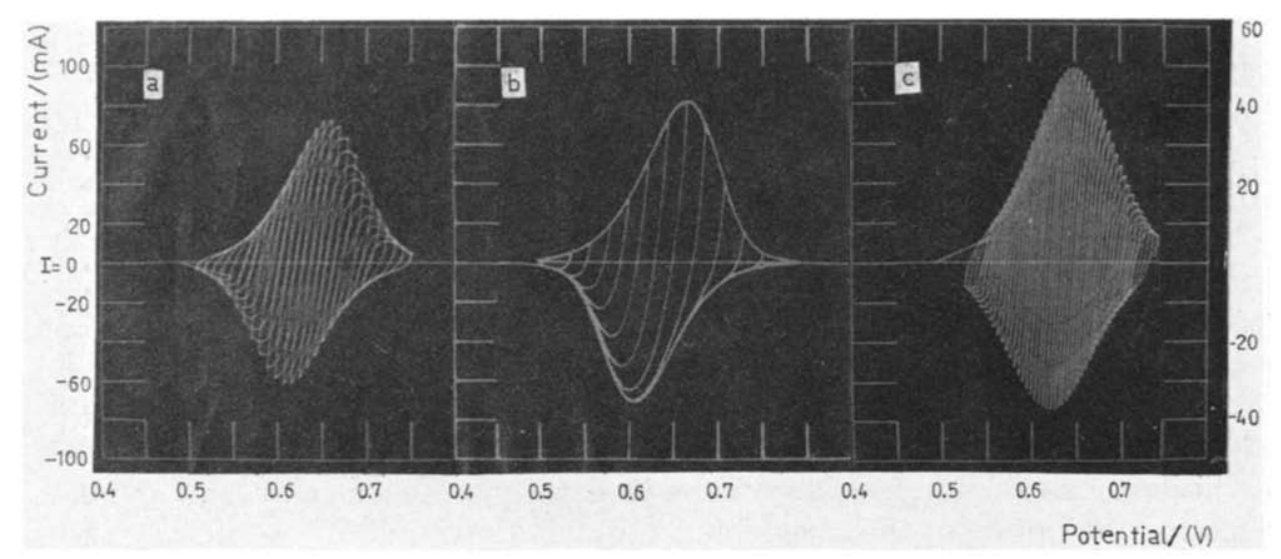

Fig. 2. (a) T.m.l.p.s. voltammogram calculated for mechanısm (I). $k_{1}=5 \times 10^{-4} \mathrm{~mA} \mathrm{~cm}^{-2}$, $k_{-1}=5 \times 10^{7} \mathrm{~mA} \mathrm{~cm}{ }^{-2}, \beta=0.5, f(\theta)=0, k=0.4 \mathrm{mC} \mathrm{cm}^{-2}, v_{\mathrm{g}}=1.5 \mathrm{~V} \mathrm{~s}^{-1}, v_{\mathrm{s}}=20 \mathrm{~V} \mathrm{~s}^{-1}$, $A_{\mathrm{s}}=0.06 \mathrm{~V}, E_{\text {eq }}=0.635 \mathrm{~V}$, electrode area $=1 \mathrm{~cm}^{2}, 290 \mathrm{~K}$ (b) L.s t.p s. voltammograms covering different potential anodic limits $v_{\mathrm{a}}=21.5 \mathrm{~V} \mathrm{~s}^{-1} ; v_{\mathrm{c}}=18.5 \mathrm{~V} \mathrm{~s}^{-1}$. The rest of the parameters as indicated in (a) Figs. $2 a$ and $b$ are referred to the same current scale. (c) T.m.l.p.s. voltammograms calculated as in (a) but $A_{\mathrm{s}}=0.03 \mathrm{~V}$.

of the anodic and cathodic currents are equal. Therefore, when the amplitude of the modulating signal decreases so that the above equality is not obeyed no relative current maxima are observed (Fig. 2c). Sometimes either the initial or the final portions of the modulated $E / I$ profiles as in Fig. $2 \mathrm{c}$ are interrupted because of the limited storage capacity of the available IBM visual unit.

When either the rate of the perturbation increases or the rate of response of the electrochemical system decreases, the instantaneous surface coverage degree at each potential lags behind the corresponding equilibrium value [2]. The shape of the $E / I$ contour depends therefore on the degree of reversibility of the electrode process, on the potential amplitude swept by the modulating signal (Figs. $3 \mathrm{a}-\mathrm{c}$ ) and on $v_{\mathrm{g}}$ (compare Figs. $3 \mathrm{a}$ and $3 \mathrm{~d}, 3 \mathrm{~b}$ and $3 \mathrm{c}, 3 \mathrm{e}$ and $3 \mathrm{f}$ ). Thus, both the anodic and the cathodic areas involved in the transient are smaller than those of the reversible case. A decrease of the amplitude of the modulating signal causes an increase of the $A_{\mathrm{a}} / A_{\mathrm{c}}$ ratio, the larger the effect the larger also the degree of irreversibility of the electrode reaction.

The difference between $\theta_{\mathrm{e}}$, the equilibrium surface coverage corresponding to the potential $E$, and $\theta(t)$, the instantaneous surface coverage, increases with the degree of irreversibility of the reaction. Hence, during the anodic scan, at the point of inversion of the modulating signal the irreversible electrochemical system still goes in the anodic direction, $\theta_{\mathbf{e}}$ being only attained when the null current potential is reached. During the cathodic scan, when this potential is exceeded a net cathodic current is observed, but the cathodic contribution remains always smaller than the anodic one.

The area of the t.m.l.p.s. $E / I$ contour for a given set of $v_{\mathrm{g}}$ and $v_{\mathrm{s}}$, is always smaller than that of the corresponding s.l.p.s. run at $v_{\mathrm{s}} \pm v_{\mathrm{g}}$; the positive sign corresponds to the anodic scan and the negative sign to the cathodic scan. Both the t.m.l.p.s. and s.l.p.s. contours can only be exactly matched when the reac- 

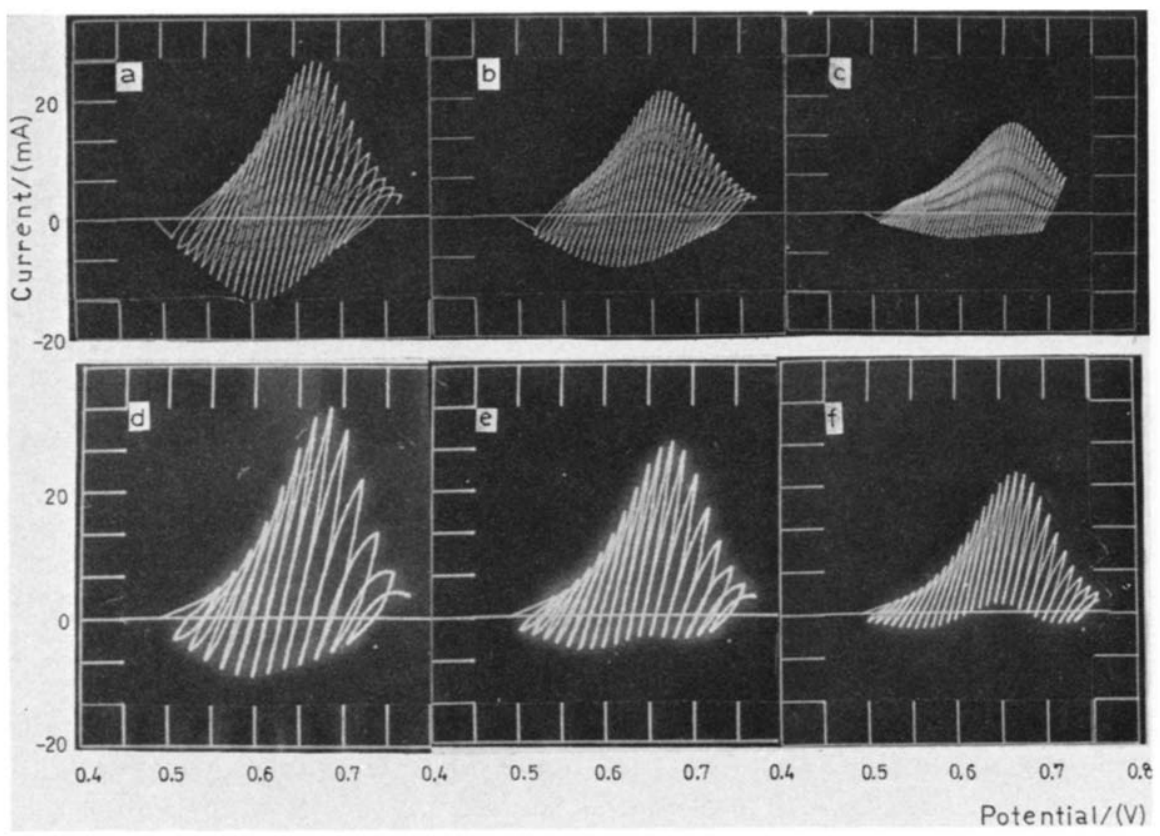

Fig. 3. T.m.l.p.s. voltammograms calculated for mechanism (I). $k_{1}=10^{-3} \mathrm{~mA} \mathrm{~cm}^{-2} ; k_{-1}=$ $10^{7} \mathrm{~mA} \mathrm{~cm}^{-2} ; \beta=0.5 ; f(\theta)=0 ; v_{\mathrm{s}}=20 \mathrm{~V} \mathrm{~s}^{-1} ; E_{\mathrm{eq}}=0.6325 \mathrm{~V} ; k=0.4 \mathrm{mC} \mathrm{cm} \mathrm{m}^{-2} ; 290 \mathrm{~K}$. $v_{\mathrm{g}}=1.5 \mathrm{~V} \mathrm{~s}^{-1} ; A_{\mathrm{s}}=0.06 \mathrm{~V}(\mathrm{a}) ; A_{\mathrm{s}}=0.045 \mathrm{~V}(\mathrm{~b}) ; A_{\mathrm{s}}=0.03 \mathrm{~V}(\mathrm{c}) ; v_{\mathrm{g}}=3.0 \mathrm{~V} \mathrm{~s}^{-1} ; A_{\mathrm{s}}=$ $0.06 \mathrm{~V}(\mathrm{~d}) ; A_{\mathrm{S}}=0.045 \mathrm{~V}(\mathrm{e}) ; A_{\mathrm{s}}=0.03 \mathrm{~V}(\mathrm{f})$.

tion is reversible. The non-coincidence comes out from the fact that at a constant $v_{\mathrm{s}}$, the t.m.l.p.s. estimulates the system yielding at a given potential a larger surface coverage degree than that obtained with s.l.p.s. at $v_{\mathrm{s}} \pm v_{\mathrm{g}}$. Therefore, $\theta(t)$ during the t.m.l.p.s. becomes closer to $\theta_{\mathrm{e}}$.

The $E / I$ displays of Fig. 3 also show that the $\Delta I / \Delta E$ slopes of each individual modulating cycle, either they be considered at $I=0$ or at the point where the modulating sweep is reversed, attain the largest value within the potential region of the current peak.

For a particular set of kinetic parameters and perturbation conditions, a decrease of the modulating signal amplitude produces a larger difference between the t.m.l.p.s. envelope and that of the corresponding s.l.p.s. This difference in Fig. 3 is more remarkable at the cathodic side than at the anodic side of the voltammogram.

Certainly, either for a completely irreversible electrochemical process or at an infinite frequency (smaller amplitude) of the modulating signal no cathodic response due to the modulating signal is observed.

The kinetic analysis of the single stage mechanism on the basis of t.m.l.p.s. data can be made as follows. The slope of the $E / I$ lines at $I=0$, for each modulating cycle can be plotted vs. In $K_{1}$, at the maximum of the $E / I$ contour (Fig. 4a). This slope depends only on the rate constants of both processes and is independent either of the amplitude of the modulating signal or of any reasonable 


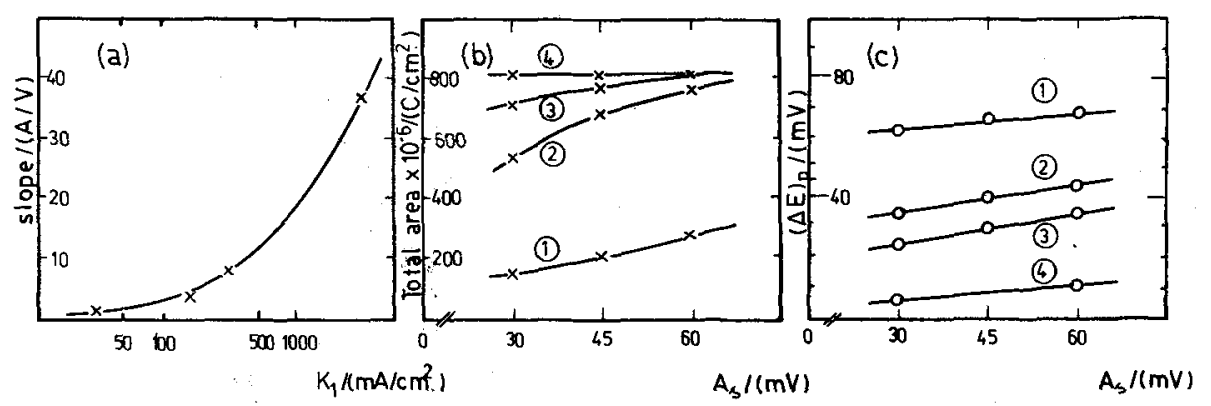

Fig. 4. Phenomenological relationships derived for mechanism (I). (1) $K_{1}=3.16 \times 10^{1} \mathrm{~mA}$ $\mathrm{cm}^{-2}$ (as in Fig. 3); (2) $K_{1}=1.58 \times 10^{2} \mathrm{~mA} \mathrm{~cm}^{-2}$ (as in Fig. 2); (3) $K_{1}=3.16 \times 10^{2} \mathrm{~mA}$ $\mathrm{cm}^{-2}$ (as in Fig. 7a); (4) $K_{1}=3.16 \times 10^{3} \mathrm{~mA} \mathrm{~cm}^{-2}$ (as in Fig. 1).

Temkin parameter related to interactions among the species covering the electrode surface. A second plot consists of the total area (charge) vs. the amplitude of the modulating signal (Fig. 4b). This plot depends on the degree of reversibility of the process. As the amplitude increases the area approaches the values expected for the reversible case. For an intermediate degree of reversibility, when the frequency of the modulating signal increases (decreasing amplitude), the area, either anodic or cathodic, decreases, but the $A_{\mathrm{a}} / A_{\mathrm{c}}$ ratio increases. Otherwise, by doubling $v_{\mathrm{g}}$ (Fig. 3 ), the area of the modulated voltammograms remains practically unaltered except when the process becomes appreciably irreversible and a perturbation of small amplitude is applied. After including in the rate equation a positive Temkin factor, keeping the same rate constants, the shape of the plot slightly approaches that of a more reversible process. Finally, a plot of the difference between the anodic and cathodic current peak potentials, $(\Delta E)_{\mathrm{p}}$, vs. the amplitude of the modulating signal is presented (Fig. $4 \mathrm{c})$. For any value of $K_{1},(\Delta E)_{\mathrm{p}}$ increases with the amplitude of the modulating signal. This difference is, however, smaller than that recorded for a comparable single triangular potential sweep (s.t.p.s.).

The plots illustrated in Fig. 4 have been calculated at $290 \mathrm{~K}$. For the same set of kinetic constants, coincident plots can be obtained at any temperature, $T$, if the potential scale is referred at $T,\left(E_{\mathrm{T}}=E_{290}(T / 290)\right)$, and the potential sweep rate is corrected accordingly, $\left[v_{T}=v_{290}(T / 290)\right]$.

(II) REACTION PATHWAY INVOLVING THE COVERAGE OF THE SURFACE BY TWO SPECIES

Let us consider a two consecutive stage pathway where two species A and B are electrochemically formed and accumulated at the electrode surface during the potential transient:

$$
\begin{aligned}
& \mathrm{M}+\mathrm{A}^{-} \rightleftharpoons \mathrm{M}(\mathrm{A})+e^{-} \\
& \mathrm{M}(\mathrm{A}) \rightleftharpoons \mathrm{M}(\mathrm{B})+e^{-}
\end{aligned}
$$

$\theta_{\mathrm{A}}$ and $\theta_{\mathrm{B}}$ are respectively, the degree of surface coverage by $\mathrm{A}$ and $\mathrm{B}$ and their 
rate of change is given by:

$$
\begin{aligned}
& \mathrm{d} \theta_{\mathrm{A}} / \mathrm{d} t=\left(K_{1} / k\right)\left\{\left(1-\theta_{\mathrm{A}}-\theta_{\mathrm{B}}\right) \exp \left[\left(1-\beta_{1}\right) E / b\right] \exp \left[-\alpha_{1} f(\theta)\right]\right. \\
& \left.\quad-\theta_{\mathrm{A}} \exp \left[-\beta_{1} E / b\right] \exp \left[\left(1-\alpha_{1}\right) f(\theta)\right]\right\}-\mathrm{d} \theta_{\mathrm{B}} / \mathrm{d} t \\
& \mathrm{~d} \theta_{\mathrm{B}} / \mathrm{d} t=\left(K_{2} / k\right)\left\{\theta_{\mathrm{A}} \exp \left[\left(1-\beta_{2}\right)\left(E-E_{\mathbf{D}}\right) / b\right] \exp \left[-\alpha_{2} g(\theta)\right]\right. \\
& \left.\quad-\theta_{\mathrm{B}} \exp \left[-\beta_{2}\left(E-E_{\mathrm{D}}\right) / b\right] \exp \left[\left(1-\alpha_{2}\right) g(\theta)\right]\right\}
\end{aligned}
$$

where

$E_{\mathrm{D}}=\left(E_{\mathrm{eq}}\right)_{2}-\left(E_{\mathrm{eq}}\right)_{1}$

The potentials are referred to the equilibrium potential of step (IIa) so that the specific rate constants are:

$k_{1}=k_{-1}=K_{1}$

$k_{2}=K_{2} \exp \left[-\left(1-\beta_{2}\right) E_{\mathrm{D}} / b\right]$

and

$k_{-2}=K_{2} \exp \left[\beta_{2} E_{\mathrm{D}} / b\right)$

The transient current density is given by:

$i=k\left(\mathrm{~d} \theta_{\mathrm{A}} / \mathrm{d} t\right)+2\left(\mathrm{~d} \theta_{\mathrm{B}} / \mathrm{d} t\right)$

The integration of this set of differential equations was made with the procedure already mentioned.

The simplest case arises when both electron transfer steps individually considered are reversible. For a s.t.p.s. experiment the $E / I$ profile depends on $E_{\mathrm{D}}$. Thus, for $E_{\mathrm{D}}$ sufficiently positive $\left(E_{\mathrm{D}} \geqslant 0.1 \mathrm{~V}\right)$ two anodic and two cathodic separated current peaks are found whose peak potentials are respectively at $\left(E_{\mathrm{eq}}\right)_{1}$ and $\left(E_{\mathrm{eq}}\right)_{2}$. Otherwise, when $E_{\mathrm{D}}<0$, and $K_{1}=K_{2}$, the $E / I$ profiles show only single asymmetric anodic and cathodic current peaks, which are antisymmetric with respect to $E_{\mathrm{D}} / 2$. The processes occur far from equilibrium, since the same amount of charge is involved within a smaller potential range. The lower the potential sweep rate the closer the peak location and the overall process approached a reversible behaviour. For the latter, the degrees of surface coverage $\theta_{\mathbf{A}}$ and $\theta_{\mathbf{B}}$ are, respectively, given by:

$\theta_{\mathrm{A}}=\left\{\exp (-E / b)+1+\exp \left[\left(E-E_{\mathrm{D}}\right) / b\right]\right\}^{-1}$

$\theta_{\mathrm{B}}=\theta_{\mathrm{A}} \exp \left[\left(E-E_{\mathbf{D}}\right) / b\right]$

Figure 5 shows the dependence of $\theta_{\mathrm{A}}$ and $\theta_{\mathrm{B}}$ on potential for $E_{\mathrm{D}}$ comprised between $-0.2 \mathrm{~V}$ and $0.5 \mathrm{~V}$. For $E_{\mathrm{D}}=-0.2 \mathrm{~V}, \theta_{\mathrm{A}}$ is always below $1 \%$ of the total surface coverage, while for $E_{\mathrm{D}}>0.1 \mathrm{~V}$ a relatively large coverage degree by species $\mathrm{A}$ is achieved at low potentials causing the occurrence of two reversible current peaks at $\left(E_{\mathrm{eq}}\right)_{1}$ and $\left(E_{\mathrm{eq}}\right)_{2}$, respectively. As $E_{\mathrm{D}}$ decreases the separation of these current peaks also decreases until for a certain values of $E_{\mathrm{D}}$, only a single current peak is observed at $E_{\mathrm{D}} / 2$. As $E_{\mathrm{D}}$ decreases the single current peak becomes sharper. Then, the response of the system to the t.m.l.p.s. is similar to that of the reversible single electron transfer mechanism already discus- 


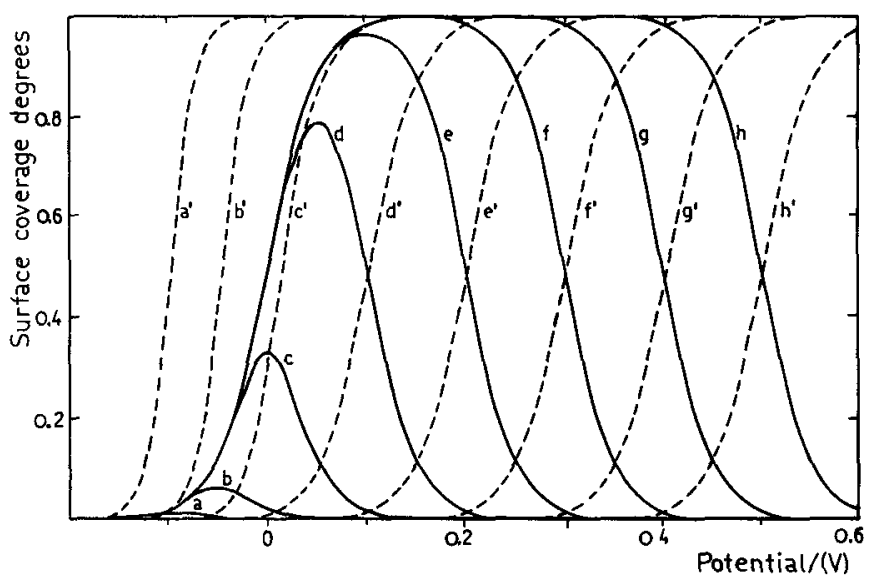

Fig. 5. Potential dependence of the partial surface coverage degrees, according to mechanism (II), for a reversible process and different $E_{\mathrm{D}}$. The potential is referred to the equilibirum potential of the first step. $\left(\mathrm{a}, \mathrm{a}^{\prime}\right) E_{\mathrm{D}}=-0.2 \mathrm{~V} ;\left(\mathrm{b}, \mathrm{b}^{\prime}\right) E_{\mathrm{D}}=-0.1 \mathrm{~V} ;\left(\mathrm{c}, \mathrm{c}^{\prime}\right) E_{\mathrm{D}}=0 \mathrm{~V} ;\left(\mathrm{d}, \mathrm{d}^{\prime}\right)$ $E_{\mathrm{D}}=0.1 \mathrm{~V} ;\left(\mathrm{e}, \mathrm{e}^{\prime}\right) E_{\mathrm{D}}=0.2 \mathrm{~V} ;\left(\mathrm{f}, \mathrm{f}^{\prime}\right) E_{\mathrm{D}}=0.3 \mathrm{~V} ;\left(\mathrm{g}, \mathrm{g}^{\prime}\right) E_{\mathrm{D}}=0.4 \mathrm{~V} ;\left(\mathrm{h}, \mathrm{h}^{\prime}\right) E_{\mathrm{D}}=0.5 \mathrm{~V}$.

Single letters refer to $\theta_{\mathrm{A}}$ and the dashed ones to $\theta_{\mathrm{B}}$.

sed. Nevertheless, the ratio of the current peak height to the current peak width at half peak height is now larger than the one referred previously. The envelopes of any of the reversible t.m.l.p.s. $E / I$ displays coincide with those recorded under s.t.p.s. at a potential sweep rate equal to $v_{\mathrm{g}} \pm v_{\mathrm{s}}$.

When the system involves.a larger degree of irreversibility the shape of the $E / I$ profiles obtained with a s.t.p.s. as well as the degree of surface coverage by species $\mathrm{A}$ and $\mathrm{B}$ depend upon $K_{1}, K_{2}$ and $E_{\mathrm{D}}$. When $K_{1}<K_{2}$ and $E_{\mathrm{D}}>0$, the anodic scan exhibits two current peaks which come closer together as the potential sweep rate increases, and eventually, superimpose into a single anodic current peak. The corresponding cathodic current peaks are in this case, affected in the reverse way. The $E / I$ displays obtained for an anodic process involving $K_{2}<K_{1}$ and $E_{\mathrm{D}}>0$, are equivalent to those already mentioned, if the reaction scheme is analysed in terms of a sequence of cathodic processes, since the same differential equation is still valid after replacing in eqn. (7) the following terms: $\left(1-\theta_{A}-\theta_{B}\right)$ by $\theta_{0}$, it being the degree of clean surface; $\theta_{B}$ by $\left(1-\theta_{A}-\theta_{0}\right)$ and $K_{1}$ plays the role of $K_{2}$. The corresponding cathodic $E / I$ contours are rotated $180^{\circ}$ with respect to those already described for the anodic potential sweep. Thus, depending on the equilibrium constant ratio, in both cases there is a limiting potential sweep rate defining the occurrence of either two anodic current peaks or two cathodic current peaks or four current peaks altogether.

The influence of $K_{2}$ and $E_{\mathrm{D}}$ on the shape of the $E / I$ profiles run for a s.t.p.s, for $K_{1}>K_{2}$, is shown in Fig. 6. For $E_{\mathrm{D}}=0$ (Figs. $6 \mathrm{~b}$ and $6 \mathrm{~d}$ ), as $K_{2}$ increases the anodic $E / I$ profile tends to define a single current peak and the accumulation of the A species at the electrode surface becomes smaller. The location of the cathodic current peak is mainly determined by the magnitude of $K_{2}$. For the cathodic scan $K_{2} \theta_{\mathrm{B}} \exp \left[-\beta_{2}\left(E-E_{\mathrm{D}}\right) / b\right]<K_{1} \theta_{\mathrm{A}} \exp \left(-\beta_{1} E / b\right)$ and, consequently, within the potential range involved, the coverage change due to step (IIb) is irreversible since a bare electrode surface is favoured instead of a surface covered by the A species. 


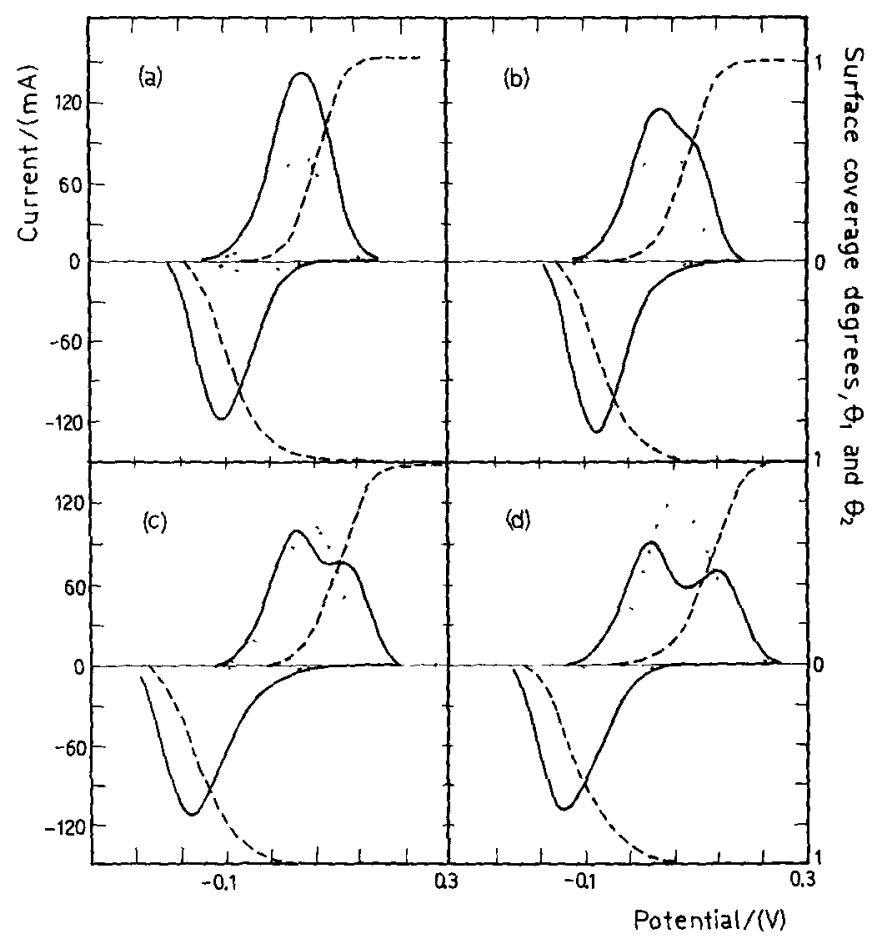

Fig. 6. $E / I$ profiles (full lines) calculated for s.t.p.s. on the basis of mechanism (II). $K_{1}=$ $3.16 \times 10^{2} \mathrm{~mA} \mathrm{~cm}^{-2} ; \beta_{1}=0.5 ; \beta_{2}=0.5 ; f(\theta)=0 ; v_{\mathrm{a}}=21.5 \mathrm{~V} \mathrm{~s}^{-1} ; v_{\mathrm{c}}=18.5 \mathrm{~V} \mathrm{~s}^{-1}$. (a) $K_{2}=3.16 \times 10 \mathrm{~mA} \mathrm{~cm}{ }^{-2}, E_{\mathrm{D}}=-0.03 \mathrm{~V} ;(\mathrm{b}) K_{2}=3.16 \times 10 \mathrm{~mA} \mathrm{~cm}^{-2}, E_{\mathrm{D}}=0 \mathrm{~V}$; (c) $K_{2}=10, E_{\mathrm{D}}=-0.03 \mathrm{~V} ;$ (d) $K_{2}=10, E_{\mathrm{D}}=0 \mathrm{~V} .290 \mathrm{~K}$. Dotted lines $\left(\theta_{\mathrm{A}}\right)$ and dashed lines $\left(\theta_{B}\right)$ indicate the potential dependence of the surface coverage degrees.

The effect of $E_{\mathrm{D}}$ on the $E / I$ profiles is also illustrated in Fig. 6. For a particular set of rate constants, the change of the anodic $E / I$ profile by an increase of $E_{\mathrm{D}}$ can be counterbalanced by a decrease of $K_{2}$ (compare Figs. $6 \mathrm{a}$ and $6 \mathrm{~b}, 6 \mathrm{c}$ and $6 \mathrm{~d}$ ).

The rate of step (IIb) increases as $K_{2} \exp \left[\left(1-\beta_{2}\right)\left(E-E_{\mathrm{D}} / b\right]\right.$ increases since $k_{2}$ increases when $\exp \left[-E_{\mathrm{D}} / b\right]$ increases. As step (IIb) only occurs appreciably after a certain $\theta_{\mathrm{A}}$ has been attained, then an increase of $k_{2}$ should produce the overlapping of the anodic current peaks (compare Figs. $6 \mathrm{c}$ and $6 \mathrm{a}, 6 \mathrm{~d}$ and $6 \mathrm{~b}$ ).

In conclusion, a single anodic current peak is obtained either when $E_{\mathrm{D}}$ diminishes or $K_{2}$ increases, while the corresponding cathodic current peak lies at more positive potentials when either $K_{2}$ or $E_{\mathrm{D}}$ increases.

A similar analysis is made for a t.m.l.p.s. The influence of the $K_{1} / K_{2}$ ratio on the theoretical displays is shown in Fig. 7. Data correspond to fixed values of both $K_{1}$ and $E_{\mathrm{D}}, K_{2}<K_{1}$ and $K_{2}$ increasing from display (a) to (c). As the $K_{1} / K_{2}$ ratio decreases the $E / I$ profiles exhibit an increase of the $A_{\mathrm{a}} / A_{\mathrm{c}}$ ratio and a decreasing symmetry, specially during the anodic potential scan.

The contribution of step (IIb) reflects on the shape of the relative current maxima occurring during each modulating cycle. The $\Delta I / \Delta E$ slope either at the point where the modulating potential reverses or at $I=0$, becomes smaller at 


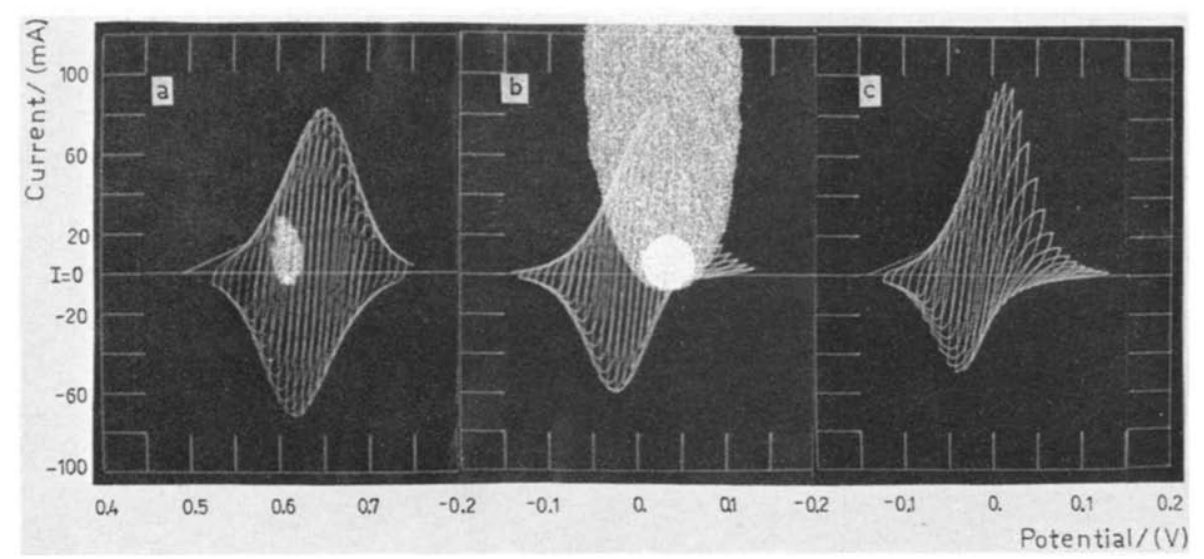

Fig. 7. T.m.l.p.s. voltammograms calculated for mechanism (II). $K_{1}=316 \times 10^{2} \mathrm{~mA} \mathrm{~cm}-2$, $\beta_{1}=\beta_{2}=0.5 ; f(\theta)=0, g(\theta)=0, v_{\mathrm{s}}=20 \mathrm{~V} \mathrm{~s}^{-1}, v_{\mathrm{g}}=15 \mathrm{~V} \mathrm{~s}^{-1}, A_{\mathrm{s}}=0.06 \mathrm{~V}, k=0.4 \mathrm{mC} \mathrm{cm}-2$, electrode area $=1 \mathrm{~cm}^{2}, 290 \mathrm{~K}$. (a) $K_{2}=0$, (b) $K_{2}=10 \mathrm{~mA} \mathrm{~cm}-2, E_{\mathrm{D}}=-0.01 \mathrm{~V}$, (c) $K_{2}=$ $3.16 \times 10 \mathrm{~mA} \mathrm{~cm}^{-2}, E_{\mathrm{D}}=-0.03 \mathrm{~V}$.

the anodic potential extreme where the influence of $K_{2}$ is much larger.

For a given $v_{\mathrm{s}}$, the ratios between $\theta_{\mathrm{A}}, \theta_{\mathrm{B}}$ and $\theta_{0}=1-\theta_{\mathrm{A}}-\theta_{\mathrm{B}}$, depend on the kinetic parameters characterising the electrochemical system. The shape of the $E / I$ display depends upon $\left(I_{1}+2 I_{2}\right)$, the sum of the partial current corresponding to steps (IIa) and (IIb). Therefore, at the initiation of the potential sweep the $E / I$ display practically exhibits the same current and $E / I$ slope as it were an electrochemical reaction involving a single surface covering species, since $\theta_{\mathbf{B}}$ only results from the previous coverage by species $A$ and $d I / d t$ is then determined by $K_{1}$. As the potential increases the average value of $\theta_{\mathrm{B}}$ also increases yielding, consequently, a diminution of the $I_{1}$ component. But the system still keeps a fast response capacity for any change in sign of the modulating signal, which reflects in the rapid change in sign of $I$. Now the $\mathrm{d} I / \mathrm{d} t$ slope is determined simultaneously by the equilibrium constants of both steps, since at the instant of the modulating signal inversion it is independent on any coverage change. Then, the $\mathrm{d} I / \mathrm{d} t$ slope changes proportionally to $2 v_{\mathrm{s}} \Sigma_{\mathrm{n}} k_{\mathrm{n}} \theta_{\mathrm{n}} \exp (E / b)$.

When the step (IIa) is faster than step (IIb), $K_{1}>K_{2}$ (Fig. 7b) the first portion of the $E / I$ display exhibits a strongly modulated effect and during the advance of the guide signal the contribution of the second process is well noticed. For $E_{\mathrm{D}}$ values sufficiently positive, an increase of $K_{2}$ produces no sensible effect in the profile region corresponding to the first reaction, which is mainly determined by $K_{1}$, except that the region of the modulated potential extends towards potentials far from $E_{\mathrm{i}}$. Otherwise, when $E_{\mathrm{D}}=0$, an increase of $K_{2}$ alters the t.m.l.p.s. $E / I$ contour (Fig. 7), and for a constant potential amplitude it causes an increase of the $A_{\mathrm{a}} / A_{\mathrm{c}}$ ratio.

When $E_{\mathrm{D}}<0$, for instance $E_{\mathrm{D}}=-0.1 \mathrm{~V}$ (Fig. 8), the first portion of the $E / I$ profile, $\left[E-\left(E_{\mathrm{eq}}\right)_{1}\right]<-0.05 \mathrm{~V}$, coincides with that seen in Fig. $7 \mathrm{~b}$, although the first modulated response involves now a very small anodic contribution of the second step. As the potential further increases a region is reached where the cathodic $E / I$ contour disappears rapidly and only the anodic $E / I$ display is re- 


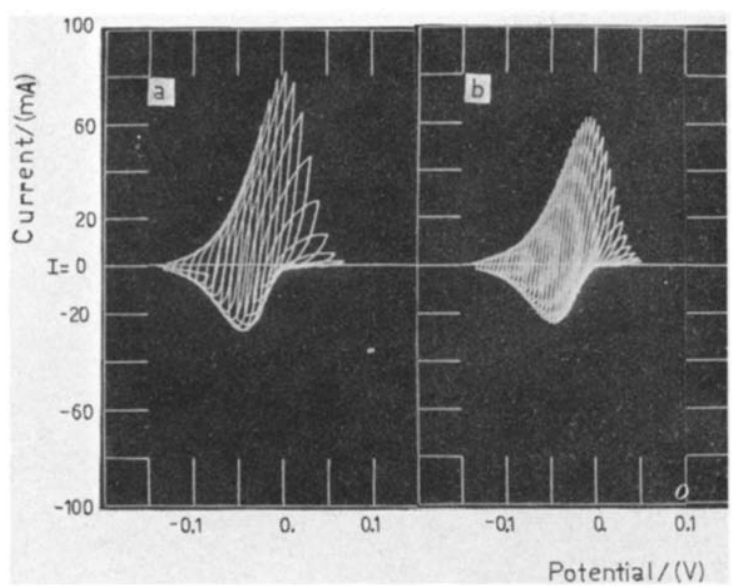

Fig. 8. T.m.l.p.s. voltammograms calculated for mechanism (II). $K_{2}=10 \mathrm{~mA} \mathrm{~cm}^{-2} ; E_{\mathrm{D}}=$ $-0.1 \mathrm{~V} ; \beta_{1}=\beta_{2}=0.5 ; f(\theta)=g(\theta)=0 ; v_{\mathrm{s}}=20 \mathrm{~V} \mathrm{~s}^{-1} ; v_{\mathrm{g}}=1.5 \mathrm{~V} \mathrm{~s}^{-1} ; k=0.4 \mathrm{mC} \mathrm{cm}^{-2}$; electrode area $=1 \mathrm{~cm}^{2} ; 290 \mathrm{~K}$. (a) $A_{\mathrm{s}}=0.06 \mathrm{~V}$; (b) $A_{\mathrm{s}}=0.03 \mathrm{~V}$.

corded there because step (IIb) is practically irreversible. When the potential amplitude decreases, the anodic $E / I$ profile diminishes appreciably. At a potential close to $\left(E_{\mathrm{eq}}\right)_{1}$ the coverage change from $\theta_{\mathrm{A}}$ to $\theta_{\mathrm{B}}$ is notoriously hindered since there $\theta_{\mathrm{B}}$ is only about 0.7 and $\theta_{\mathrm{A}}$ already exceeds $\theta_{0}$.

When step (IIb) is faster than step (IIa) $K_{1}<K_{2}$ the t.m.l.p.s. $E / I$ profiles obtained under different $E_{\mathrm{D}}$ conditions are those illustrated in Figs. 9 and 10. For $E_{\mathrm{D}}>0\left(E_{\mathrm{D}}=0.1 \mathrm{~V}\right)($ Figs. $9 \mathrm{c}, \mathrm{d})$, the first region of the $E / I$ display exhibits practically no modulated contribution, but as the guide sweep reaches higher potential regions it defines both the anodic and the cathodic components which are related to the second equilibrium step. It this case, when the potential amplitude decreases the cathodic area decreases more markedly than the anodic area.

The magnitude of the corresponding $A_{\mathrm{a}} / A_{\mathrm{c}}$ ratio depends on the degree of irreversibility of step (IIb). For $E_{\mathrm{D}}=0$, within the first potential region, $\left[E-\left(E_{\mathrm{eq}}\right)_{1}\right] \simeq-0.1 \mathrm{~V}$ (Figs. $\left.10 \mathrm{a}, \mathrm{b}\right)$, the $E / I$ display corresponds to an irreversible reaction, while a modulated current contribution appears at higher potentials. The $A_{\mathrm{a}} / A_{\mathrm{c}}$ ratio increases quite markedly when the potential amplitude diminishes. Therefore, the first region of the modulated $E / I$ profile is mainly determined by $K_{1}$ since the amount of $\theta_{\mathrm{B}}$ produced by step (IIb) is small. In this potential region, the $\mathrm{d} I / \mathrm{d} E$ slopes either at the modulating signal inversion or at $I=0$, are similar to those already found in the process involving a coverage by a single species for the same $K_{1}$ value. As the guide potential sweep goes further the two processes are still observed but the modulated response of step (IIb) becomes now better defined. The overall reaction implies a t.m.l.p.s. $E / I$ profile where the $A_{\mathrm{a}} / A_{\mathrm{c}}$ changes with the potential amplitude as it would correspond to a slightly more reversible process involving a surface coverage by a single species for the same $K_{1}$ value. On doubling $v_{\mathrm{g}}$, the response of the overall electrochemical system becomes more irreversible, because the slowness of the surface coverage by $\theta_{\mathrm{A}}$ and consequently, the contribution of the second revers- 


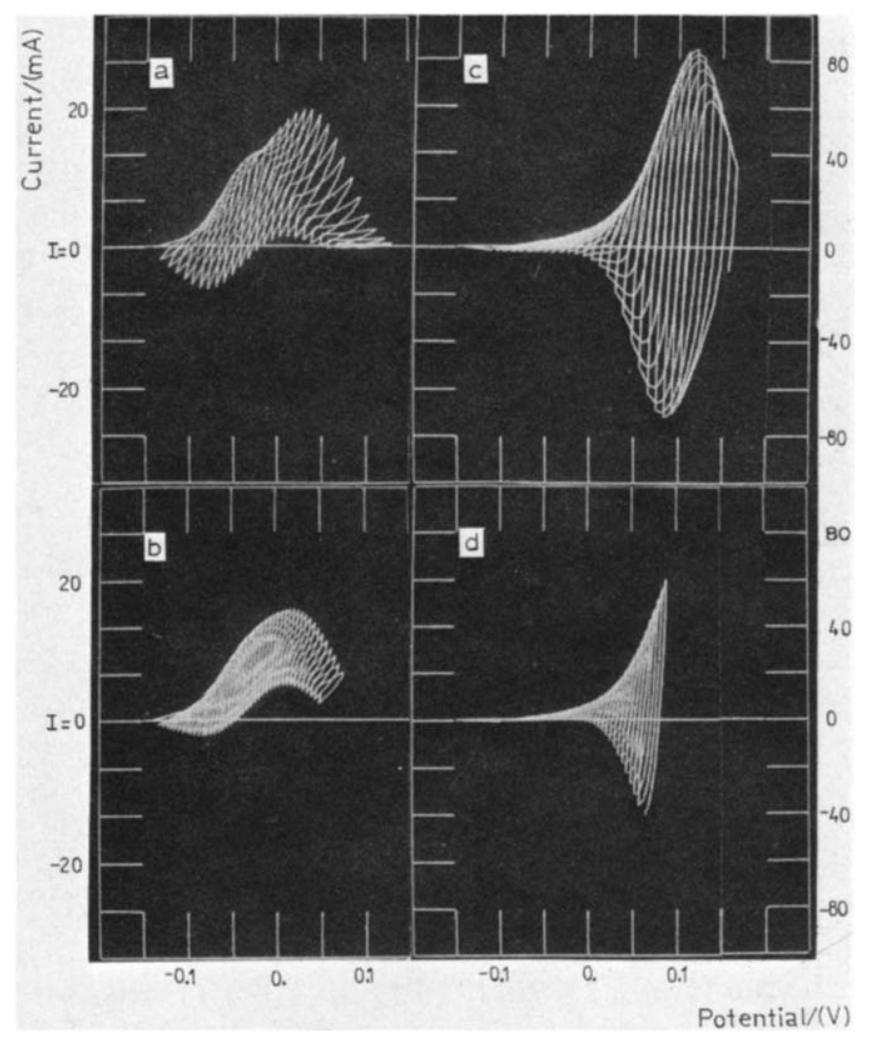

Fig. 9. T.m.l.p.s. voltammograms calculated for mechanism (II). $K_{1}=10 \mathrm{~mA} \mathrm{~cm}{ }^{-2} ; K_{2}=$ $3.16 \times 10^{2} \mathrm{~mA} \mathrm{~cm}^{-2} ; \beta_{1}=\beta_{2}=0.5 ; f(\theta)=g(\theta)=0 ; v_{\mathrm{s}}=20 \mathrm{~V} ; v_{\mathrm{g}}=1.5 \mathrm{~V} ; k=0.4 \mathrm{mC} \mathrm{cm}^{-2}$; electrode area $=1 \mathrm{~cm}^{2} ; 290 \mathrm{~K}$. (a) $E_{\mathrm{D}}=-0.1 \mathrm{~V}, A_{\mathrm{s}}=0.06 \mathrm{~V}$; (b) $E_{\mathrm{D}}=-0.1 \mathrm{~V}, A_{s}=0.03 \mathrm{~V}$; (c) $E_{\mathrm{D}}=0.1 \mathrm{~V}, A_{\mathrm{s}}=0.06 \mathrm{~V}$; (d) $E_{\mathrm{D}}=0.1 \mathrm{~V}, A_{\mathrm{s}}=0.03 \mathrm{~V}$.

ible step becomes smaller. This effect can be readily seen after comparing Figs. 10 and 3.

When $E_{\mathrm{D}}<0\left(E_{\mathrm{D}}=-0.1 \mathrm{~V}\right)$ (Figs. 9a, b), the first portion of the $E / I$ profile still exhibits an irreversibility which increases during the potential excursion. For a $0.06 \mathrm{~V}$ potential amplitude, the initial portion of the anodic $E / I$ display presents a double contour (Figs. 9a, b) similar to that also seen in Figs. 10a and $\mathrm{b}$, due to the different kinetic response and surface coverage degree of steps (IIa) and (IIb) at the inversion of the modulating signal. Accordingly the total surface coverage is principally determined by $K_{1}$. The first step exhibits now an increasing degree of irreversibility since the $\theta_{\mathrm{B}} / \theta_{\mathrm{A}}$ ratio increases. The total surface coverage lags behind its equilibrium value, but the $\theta-\theta_{\mathrm{e}}$ difference is appreciably reduced during the cathodic half-cycle, when $\theta_{\mathrm{A}}$ and $\theta_{\mathbf{B}}$ both approach their corresponding equilibrium values. Hence within the potential region where both $\theta_{\mathrm{A}}$ and $\theta_{\mathbf{B}}$ become appreciable when the modulating signal is inverted the significant contribution of the second step originates the double $E / I$ profile. Simultaneously, the anodic current contribution of step (IIa) is progressively smaller. The net effect diminishes as the potential amplitude decreases. Thus, 


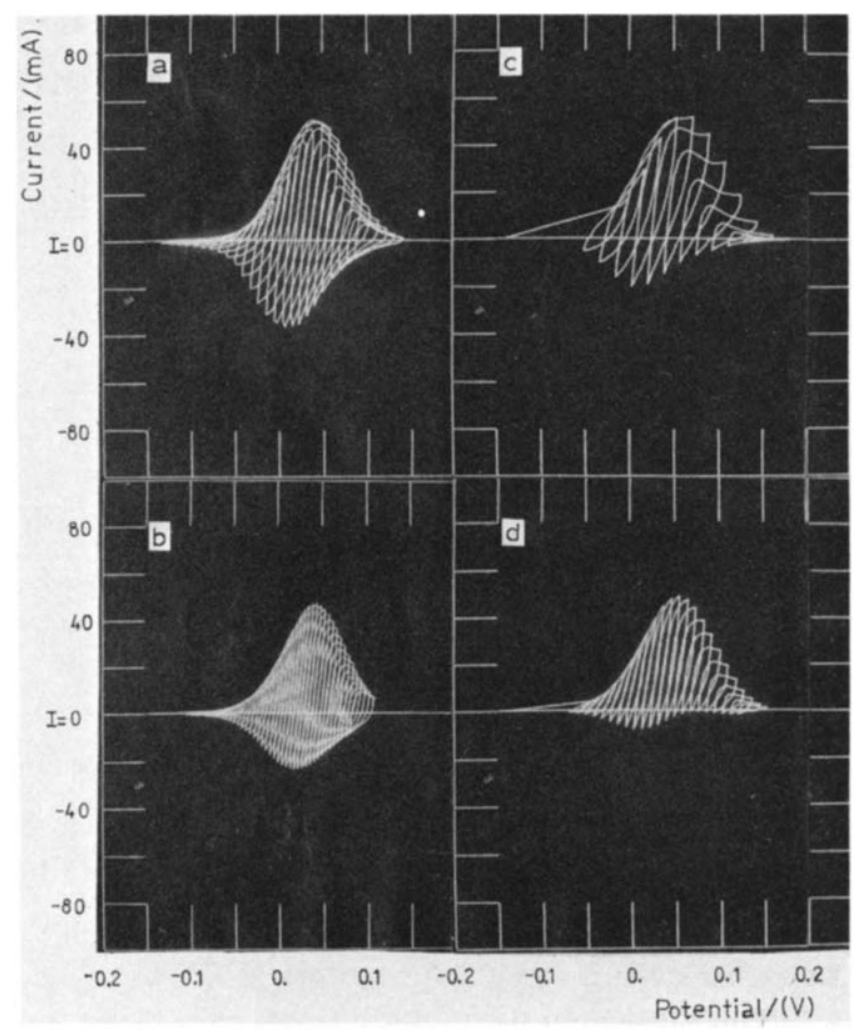

Fig. 10. T.m.l.p.s. voltammograms calculated for mechanism (II). (a) $E_{\mathrm{D}}=0 \mathrm{~V}, A_{\mathrm{s}}=0.06 \mathrm{~V}$, $v_{\mathrm{g}}=1.5 \mathrm{~V} \mathrm{~s}^{-1}$; (b) $E_{\mathrm{D}}=0 \mathrm{~V}, A_{\mathrm{s}}=0.03 \mathrm{~V}, v_{\mathrm{g}}=1.5 \mathrm{~V} \mathrm{~s}^{-1}$; (c) $E_{\mathrm{D}}=0 \mathrm{~V}, A_{\mathrm{s}}=0.06 \mathrm{~V}, v_{\mathrm{g}}=$ $3 \mathrm{~V} \mathrm{~s}^{-1}$; (d) $E_{\mathrm{D}}=0 \mathrm{~V}, A_{\mathrm{s}}=0.03 \mathrm{~V}, v_{\mathrm{g}}=3 \mathrm{~V} \mathrm{~s}^{-1}$. The rest of the kinetic parameters as indicated in Fig. 9.

for any value of the total surface coverage, the possibility of reaching either the potential or the time required to attain $\theta_{\mathrm{e}}$ during the subsequent cathodic halfcycle, is lower. Therefore, during the modulating ramp inversion, the contribution of the second equilibrium step is reduced and the first step cannot be individually defined in the $E / I$ profile but it is enclosed in the overall $E / I$ contour. At more anodic potential, the anodic half-cycles of the modulating signal show a region involving a minimum current variation (hold-up) defining an imaginary $E / I$ contour which attains a maximum at the equilibrium potential of the reversible step (IIb).

(III) MECHANISM OF REACTION INVOLVING A DUAL COVERAGE AND A CHEMICAL TRANSFORMATION FROM THE SURFACE SPECIES RELATED TO $\theta_{A}$ TO THAT RELATED TO $\theta_{\mathrm{B}}$

Let us consider now the following reaction pathway involving two consecutive electron transfer steps and an alternative second order chemical transformation from the surface species firstly produced into the second one which, under the 
present circumstances, is the most stable:

$$
\begin{aligned}
& \mathrm{M}+\mathrm{A}^{-} \rightleftharpoons \mathrm{M}(\mathrm{A})+e^{-} \\
& \mathrm{M}(\mathrm{A}) \rightleftharpoons \mathrm{M}(\mathrm{B})+e^{-} \\
& 2 \mathrm{M}(\mathrm{A}) \rightarrow \mathrm{M}(\mathrm{B})+\mathrm{M}
\end{aligned}
$$

The rates of the degrees of surface coverages are now given by:

$$
\begin{aligned}
& \mathrm{d} \theta_{\mathrm{A}} / \mathrm{d} t=\left(K_{1} / k\right)\left\{\left(1-\theta_{\mathrm{A}}-\theta_{\mathrm{B}}\right) \exp \left[\left(1-\beta_{1}\right) E / b\right] \exp \left[-\alpha_{1} f(\theta)\right]\right. \\
& \left.\quad-\theta_{\mathrm{A}} \exp \left[-\beta_{1} E / b\right] \exp \left[\left(1-\alpha_{1}\right) f(\theta)\right]\right\}-\mathrm{d} \theta_{\mathrm{B}} / \mathrm{d} t-C_{3} \theta_{\mathrm{A}}^{2} \exp \left[\alpha_{3} h(\theta)\right] \\
& \mathrm{d} \theta_{\mathrm{B}} / \mathrm{d} t=\left(K_{2} / k\right)\left\{\theta_{1} \exp \left[\left(1-\beta_{2}\right)\left(E-E_{\mathrm{D}}\right) / b\right] \exp \left[-\alpha_{2} g(\theta)\right]\right. \\
& \quad-\theta_{\mathrm{B}} \exp \left[-\beta_{2}\left(E-E_{\mathrm{D}}\right) / b\right] \exp \left[\left(1-\alpha_{2}\right) g(\theta)\right]+C_{3} \theta_{\mathrm{A}}^{2} \exp \left[\alpha_{3} h(\theta)\right]
\end{aligned}
$$

and the current density is given by eqn. (10). $C_{3}$ is the specific rate constant of the chemical process and

$f(\theta)=\Delta G_{\mathrm{A}} / R T$

$g(\theta)=\left(\Delta G_{\mathrm{B}}-\Delta G_{\mathrm{A}}\right) / R T$

and

$h(\theta)=\left(\Delta G_{\mathrm{B}}-2 \Delta G_{\mathrm{A}}\right) / R T$

are the rate of changes of $\Delta G_{1}$, the apparent standard adsorption free energies with coverage corresponding to each reaction step. The theoretical $E / I$ profiles are obtained after numerically solving the set of differential eqns. (13) using different kinetic data.

The theoretical displays shown in Fig. 11 correspond to different s.t.p.s. of increasing potential amplitude and values of $C_{3}$ ranging from 0 to $500 \mathrm{~s}^{-1}$. The surface coverage degrees attained in these runs are comprised between 0 and 1 .

The potential of the cathodic current peak corresponding to the largest potential excursion remains unchanged since it is determined only by $K_{2}$. The anodic current peak potential lies at lower potentials than that of the equivalent current peak previously discussed for mechanism (II). Therefore for mechanism (III), when $C_{3}$ increases, both current peaks become closer.

The second order chemical transformation [step (IIIc)] produces a relatively small contribution to the overall reaction at $\theta_{\mathrm{A}} \simeq 0$. As a matter of fact if $\theta_{\mathrm{A}}$ is determined by a reversible first order electron transfer step, the potential dependence of the term $K_{2} \theta_{\mathrm{A}}^{2} \exp (E / b)$ becomes smaller than that of the sec ond order term $C_{3} \theta_{\mathrm{A}}^{2}$ for $\theta_{\mathrm{A}}<0.2$. Consequently, when the amplitude of the s.t.p.s. decreases, the cathodic scan exhibits a relatively larger contribution of step (IIIa), since species $A$ is the initial reactive.

The low amplitude s.t.p.s. response for mechanism (III) under Temkin adsorption conditions is seen in Fig. 12, where the standard adsorption free energies corresponding to $\mathrm{A}$ and $\mathrm{B}$ change with $\theta_{\mathrm{A}}$ and $\theta_{\mathrm{B}}$ according to:

$$
\begin{aligned}
& \Delta G_{\mathrm{A}} / R T=g_{1}\left(\theta_{\mathrm{A}}+\theta_{\mathrm{B}}\right) \\
& \Delta G_{\mathrm{B}} / R T=g_{2}\left(\theta_{\mathrm{A}}+\theta_{\mathrm{B}}\right)
\end{aligned}
$$

When the second electron transfer step is slower than the chemical step, 


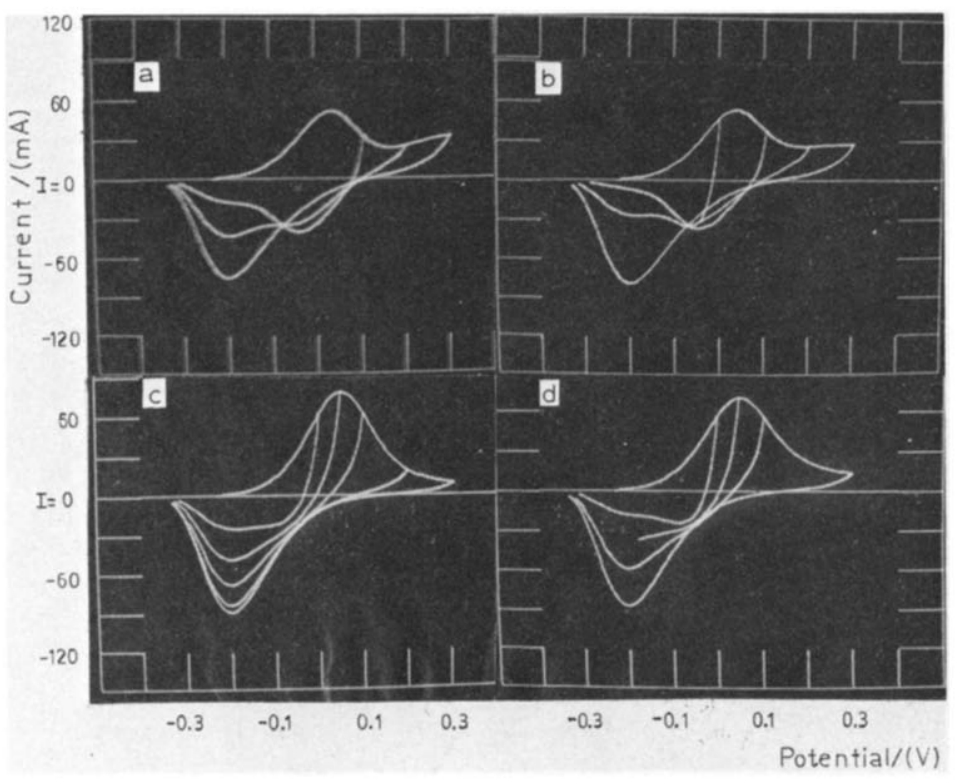

Fig. 11. S.t.p.s. voltammograms covering different potential amplitudes for mechanism (III). $K_{1}=2 \times 10^{2} \mathrm{~mA} \mathrm{~cm}^{-2}, K_{2}=6 \mathrm{~mA} \mathrm{~cm}^{-2}, E_{\mathrm{D}}=0.02 \mathrm{~V} ; \beta_{1}=0.5 ; \beta_{2}=0.6 ; f(\theta)=g(\theta)=0 ;$ $v_{\mathrm{a}}=v_{\mathrm{c}}=21.5 \mathrm{~V} \mathrm{~s}^{-1} ; k=0.4 \mathrm{mC} \mathrm{cm}^{-2}$; electrode area $=1 \mathrm{~cm}^{2} ; 513 \mathrm{~K}$. (a) $C_{3}=0 ;$ (b) $C_{3}=$ $25 \mathrm{~s}^{-1}$, (c) $C_{3}=250 \mathrm{~s}^{-1}$; (d) $C_{3}=500 \mathrm{~s}^{-1}$.

$K_{2} \theta_{\mathrm{A}} \exp \left[\left(1-\beta_{2}\right)\left(E-E_{\mathrm{D}}\right) / b\right]<<C_{3} \theta_{\mathrm{A}}^{2}$, the anodic $E / I$ profile is independent of $E_{\mathrm{D}}$, but is changes the position of the cathodic current peak which depends also on $K_{2}$.

Let us consider now a t.m.l.p.s. $E / I$ profile for the simplest case where $k_{2}=0$ (Figs. 13a, b). A modulating current response is only observed if step (IIIa) is fast. Furthermore, species B which comes from step (IIIc) can be electrochemi-

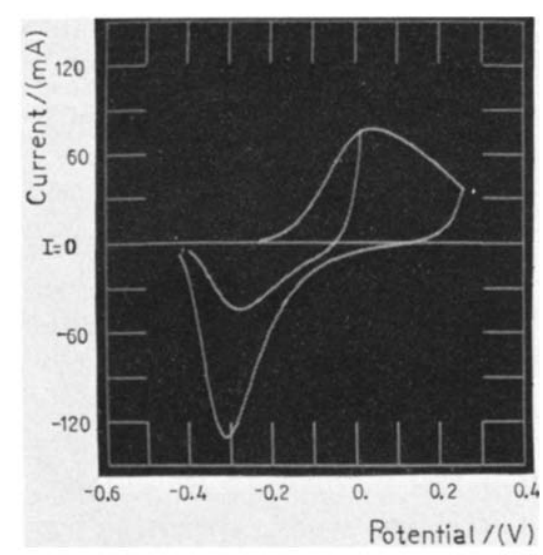

Fig. 12. S.t.p.s. voltammograms for mechanism (III). $K_{1}=1 \times 10^{3} \mathrm{~mA} \mathrm{~cm}^{-2} ; K_{2}=8 \mathrm{~mA}$ $\mathrm{cm}^{-2} ; E_{\mathrm{D}}=-0.02 \mathrm{~V} ; C_{3}=3 \times 10^{3} \mathrm{~s}^{-1} ; \beta_{1}=\beta_{2}=\alpha_{1}=\alpha_{2}=0.5 ; g_{1}=10 ;\left(g_{2}-g_{1}\right)=-2$; $v_{2}=v_{\mathrm{c}}=60 \mathrm{~V} \mathrm{~s}^{-1} ; k=0.2 \mathrm{mC} \mathrm{cm}^{-2}$; electrode area $=1 \mathrm{~cm}^{2} ; 513 \mathrm{~K}$. 


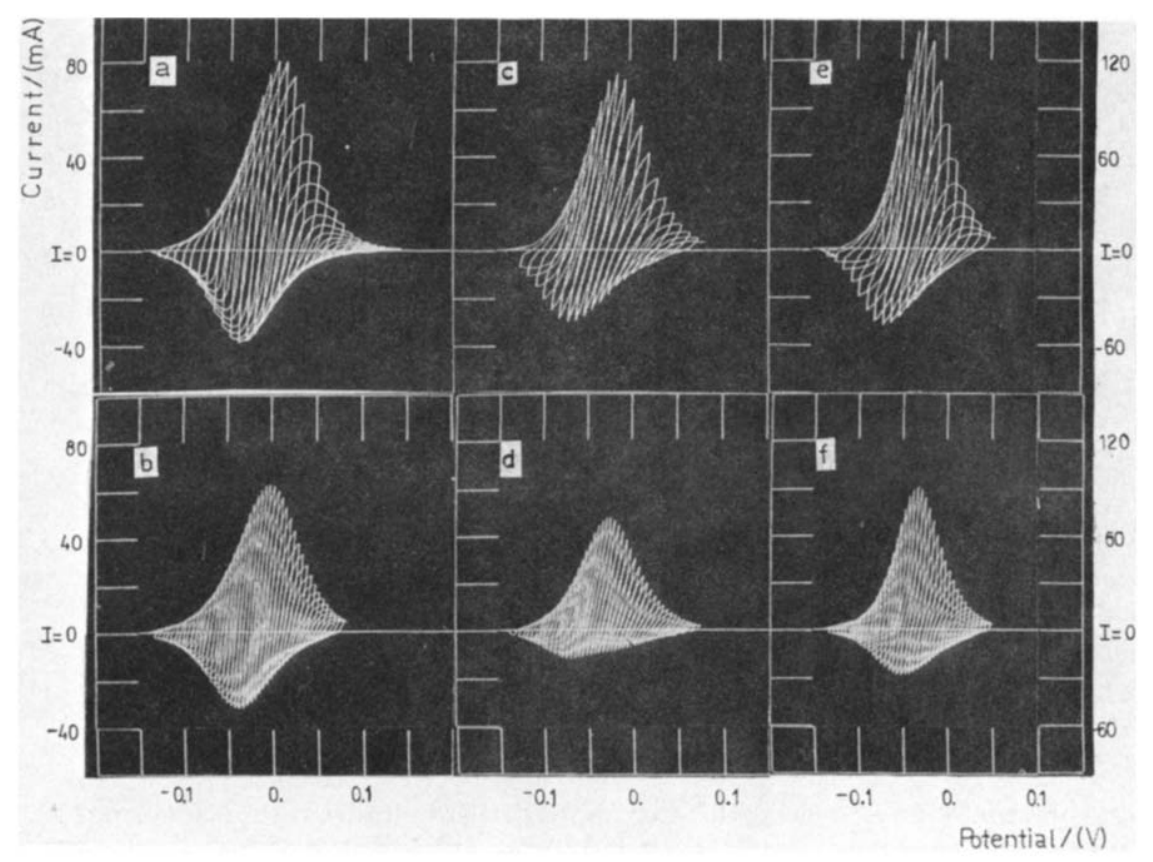

Fig. 13. T.m.l.p.s. voltammograms for mechanısm (III). $k_{2}=0, k_{-2}=10 \mathrm{~mA} \mathrm{~cm}^{-2}, \beta_{1}=$ $\beta_{2}=0.5 ; f(\theta)=g(\theta)=0 ; v_{\mathrm{s}}=20 \mathrm{~V} \mathrm{~s}^{-1}, v_{\mathrm{g}}=15 \mathrm{~V} \mathrm{~s}^{-1}, k=0.4 \mathrm{mC} \mathrm{cm}^{-2}$; electrode area $=$ $1 \mathrm{~cm}^{2}, 290 \mathrm{~K}$.

(a) $K_{1}=3.16 \times 10^{2} \mathrm{~mA} \mathrm{~cm}^{-2}, C_{3}=4 \times 10^{2} \mathrm{~s}^{-1}, A_{\mathrm{s}}=0.06 \mathrm{~V}$;

(b) $K_{1}=3.16 \times 10^{2} \mathrm{~mA} \mathrm{~cm}^{-2}, C_{3}=4 \times 10^{2} \mathrm{~s}^{-1}, A_{\mathrm{s}}=0.03 \mathrm{~V}$;

(c) $K_{1}=3.16 \times 10^{2} \mathrm{~mA} \mathrm{~cm}^{-2}, C_{3}=8 \times 10^{3} \mathrm{~s}^{-1}, A_{\mathrm{s}}=0.06 \mathrm{~V}$,

(d) $K_{1}=3.16 \times 10^{2} \mathrm{~mA} \mathrm{~cm}-2, C_{3}=8 \times 10^{3} \mathrm{~s}^{-1}, A_{\mathrm{s}}=0.03 \mathrm{~V}$;

(e) $K_{1}=3.16 \times 10^{3} \mathrm{~mA} \mathrm{~cm}-2, C_{3}=8 \times 10^{3} \mathrm{~s}^{-1}, A_{\mathrm{s}}=0.06 \mathrm{~V}$;

(f) $K_{1}=3.16 \times 10^{3} \mathrm{~mA} \mathrm{~cm}^{-2}, C_{3}=8 \times 10^{3} \mathrm{~s}^{-1}, A_{\mathrm{s}}=0.03 \mathrm{~V}$.

cally transformed into species A. Under these circumstances the $E / I$ display looks like that already seen for the reaction mechanism (II). This general coincidence, however, is fortuituous since the chemical step is conceived as a second order process with respect to $\theta_{\mathrm{A}}$, while in mechanism (II) the electrochemical conversion of species $A$ into species $B$ depended principally on the term $K_{2} \theta_{\mathrm{A}} \exp \left[\left(1-\beta_{2}\right)\left(E-E_{\mathrm{D}}\right) / b\right]$.

The initial portion of the cathodic $E / I$ contour displayed in Fig. 13a compares well with that shown in Fig. $7 \mathrm{c}$, for both runs involve a low value of $\theta_{\mathrm{A}}$. The amount of $\theta_{\mathrm{B}}$ is, however, already enough to give an $I_{2}$ component which actually modified the $E / I$ profile corresponding to the reduction of species $\mathrm{A}$. Nevertheless, when the potential increases, the $I_{2}$ contribution, in Fig. 7c, becomes notoriously larger than in Fig. 13a. The anodic right portion of the $E / I$ display of Fig. 13a is similar to that of Fig. 7b, the latter involving a $K_{2}$ whose value is lower than that of Fig. 7c. Otherwise, the cathodic profile shown in Fig. 7b practically corresponds to that obtained for mechanism (I) since the contribution of the second anodic step is smaller than that shown in Fig. 13a.

The increase of $C_{3}$ (compare Figs. 13a and 13c, 13b and 13d) modifies the 
shape of the overall t.m.l.p.s. $E / I$ profile in the direction expected for an electrochemical process of increasing irreversibility. This effect becomes more evident by changing the amplitude of the modulating signal (compare Figs. 13a and $13 \mathrm{~b}, 13 \mathrm{c}$ and 13d). When the latter decreases the total area changes so that the $A_{\mathrm{a}} / A_{\mathrm{c}}$ ratio increases, the largest change corresponding to the cathodic envelope.

The effect of $K_{1}$ on the t.m.l.p.s. display is also recorded (compare Figs. 13c and $13 \mathrm{e}, 13 \mathrm{~d}$ and $13 \mathrm{f}$ ). At the inversion of the modulating ramp, particularly when the anodic partial sweeps are initiated, the contribution of the first step produces a more abrupt change of the $\mathrm{d} I / \mathrm{d} E$ slope, the larger the ratio of step (IIIa) and (IIIc) becomes.

After comparing these $E / I$ profiles with those for mechanism (II) one concludes that the irreversibility of the second process principally influences the end of the modulating response through an increasing asymmetry of the cathodic $E / I$ contour (Figs. $7 \mathrm{~b}, \mathrm{c}$ and $8 \mathrm{a}, \mathrm{b}$ ). But when the species B is chemically formed through step (IIIc) the overall t.m.l.p.s. E/I contour exhibits no depression of the cathodic branch when the region of the largest irreversibility is attained.

\section{CONCLUSIONS}

The preceding analysis shows the outstanding characteristics of the t.m.l.p.s. technique to reveal intermediate steps either chemical or electrochemical in those non-diffusion controlled electrochemical reactions where the amount of charge involved is of the order of a monolayer thickness.

The t.m.l.p.s. displays the current response of the system either to changing potential amplitude at a fixed $v_{\mathrm{s}}$ or to changing $v_{\mathrm{s}}$ while keeping the potential amplitude constant, without implying an important variation in the potential and time conditions involved in the formation of the different species. Nevertheless, although the rapid visual display of the $E / I$ characteristics, is possible any careless straightforward comparison between theoretical and experimental data generates ambiguous quantitative kinetic information, because of the large number of adjustable parameters involved in the analysis of complex reaction mechanisms. This drawback however is partially overcome when the t.m.l.p.s. technique is applied together with another potential perturbation such as the s.l.p.s. or the s.t.p.s. voltammetry, which implies a change of potential scan rate corresponding to a variation of the time required to form the electrode surface species. Therefore, during the t.m.l.p.s. the system is perturbed within a certain potential range, without modifying substantially the time required for the formation of the intermediate species, which mainly depends on the rate $v_{\mathrm{g}}$.

In this respect for the reaction mechanisms involving the formation of two surface species it is interesting to emphasize the coincidence of the initial portion of the anodic $E / I$ profiles obtained either with s.t.p.s. of increasing amplitude or with the t.m.l.p.s. techniques started from $E_{\mathrm{i}}$ (Fig. 14). This means that within the potential region where the profiles are coincident the overall anodic reaction behaves close to a simple reversible process. The current peaks observed for t.m.l.p.s. are located at the equilibrium potential of the first electron transfer reaction. The occurrence of the second contribution is actually noticed at higher anodic potentials and as it behaves irreversible, there is a net anodic contribu- 


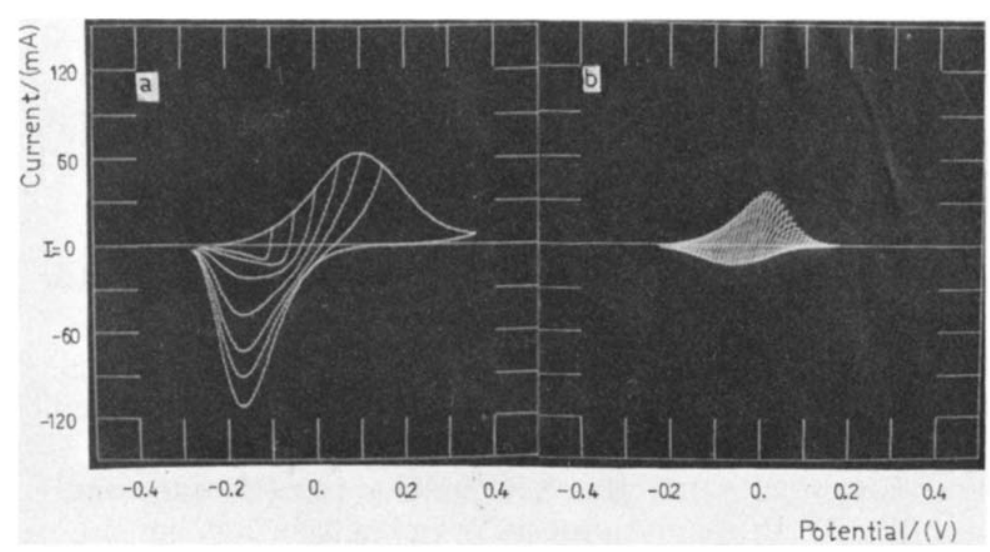

Fig. 14. Comparison between s.t.l.p.s. and t.m.l.p.s. voltammograms for mechanism (III). $K_{1}=2 \times 10^{2} \mathrm{~mA} \mathrm{~cm}^{-2} ; K_{2}=9 \mathrm{~mA} \mathrm{~cm}-2 ; E_{\mathrm{D}}=0 \mathrm{~V}, C_{3}=2 \times 10^{2} \mathrm{~s}^{-1} ; \beta_{1}=\beta_{2}=\alpha_{1}=\alpha_{2}=$ $0.75 ;\left(\Delta G_{\mathrm{A}} / R T\right)=2\left(\theta_{1}+\theta_{1}^{2}\right) ;\left(\Delta G_{\mathrm{B}} / R T\right)=0 ; k=0.4 \mathrm{mC} \mathrm{cm}-2$; electrode area $=1 \mathrm{~cm}^{2}$; $290 \mathrm{~K}$. (a) $v_{\mathrm{a}}=v_{\mathrm{c}}=21.5 \mathrm{~V} \mathrm{~s}^{-1}$; (b) $v_{\mathrm{g}}=1.5 \mathrm{~V} \mathrm{~s}^{-1}, v_{\mathrm{s}}=20 \mathrm{~V} \mathrm{~s}^{-1}$.

tion at the end of each modulating cycle.

With the t.m.l.p.s. the time dependence of $\theta_{\mathrm{A}}$ changes if the process involves one or two covering species. When there is only one species (Fig. 15a) the magnitude of $\theta_{\mathrm{A}}$ fluctuates along a monotonously increasing function which exhibits an inflection point. When the reaction is reversible, the latter lies at $\theta_{\mathrm{A}}=0.5$. For the case of two coverages (Fig. 15b) the initial portion of the curve coincides with that shown in Fig. 15a but the occurrence of the second electron transfer process causes a maximum at $\theta_{\mathrm{A}}=0.24$.

The maximum $\theta_{\mathrm{A}}$ value and its largest time variation occurs in a potential region close to the equilibrium potential related to species $\mathrm{A}$. Since the species

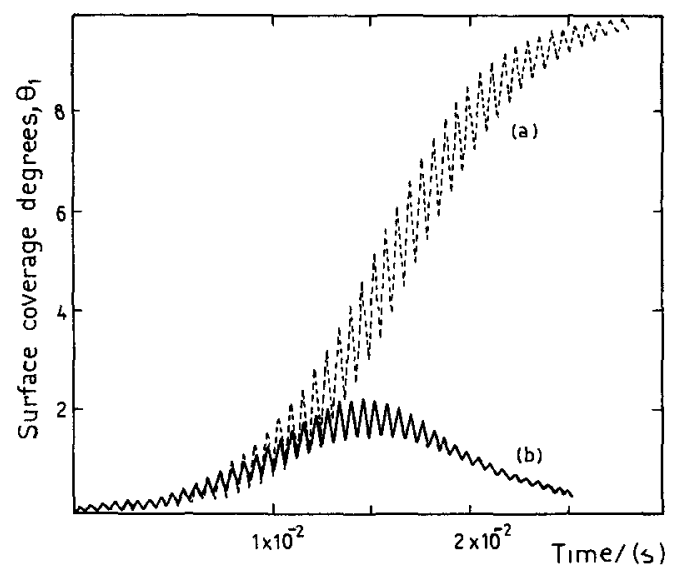

Fig. 15. Potential (time) dependence of the degrees of surface coverage for the t.m.l.p.s. technique. (a) The dependence of $\theta_{A}$ predicted according to mechanism (I); $K_{1}=2 \times 10^{2}$ $\mathrm{mA} \mathrm{cm}^{-2}$. (b) The dependence of $\theta_{\mathrm{A}}$ predicted according to mechanism (III) and the kinetic conditions indicated in Fig. 14. 
B blocks the surface to species A, the equilibrium related to the first electron transfer reaction is attained on a restricted clean electrode surface. As a first approximation, $\left(E_{\mathrm{eq}}\right)_{1}$ of species A lies at a potential slightly higher than that corresponding to the maximum $\theta_{\mathrm{A}}$. This is equivalent establishing a low limiting value for $\left(E_{\mathrm{eq}}\right)_{1}$.

\section{ACKNOWLEDGEMENTS}

The Institute (INIFTA) is patronized by the following institutions: Universidad Nacional de La Plata, Consejo Nacional de Investigaciones Cientificas y Técnicas and Comisión de Investigaciones Cientificas (Pcia. de Bs.As.). This work was partially supported by the Regional Program for the Scientific and Technological Development of the American State Organization. The cooperation and facilities of the Centro de Técnicas Analógico-Digitales (ing. A. Quijano) is acknowledged.

\section{REFERENCES}

1 F.C. Will and C. Knorr, Z. Elektrochem., 64 (1960) 258.

2 S. Srınvasan and E. Gileadi, Electrochım. Acta, 11 (1966) 321.

3 A.M. Baticle, R. Rudell, P. Vennerau and J. Vernières, J. Electroanal. Chem., 41 (1973) 51.

4 A.M. Baticle, R. Rudell, P. Vennerau and J. Vernières, J. Electroanal. Chem., 45 (1973) 439.

5 A.J. Appleby, J. Electrochem. Soc., 120 (1973) 1205.

6 N.R. de Tacconi, A.J. Calandra and A.J. Arvia, J. Electroanal. Chem., 51 (1974) 25.

7 N.R. de Tacconi, A.J. Calandra and A.J. Arvia, J. Electroanal. Chem., 57 (1974) 325.

8 H. Angerstein-Kolzlowska, B.E. Conway and W.B.A. Sharp, J. Electroanal. Chem., 43 (1973) 9.

9 C.M. Ferro, A.J. Calandra and A.J. Arvia, J. Electroanal. Chem., 59 (1975) 239.

10 H. Angerstein-Kozlowska, B. MacDougall and B.E. Conway, J. Electroanal. Chem., 39 (1972) 287.

11 B.E. Conway and S. Gottesfeld, J. Chem. Soc. Faraday Trans. I, 69 (1973) 1090.

12 B.E. Conway, H. Angerstein-Kozlowska, F.C. Ho, J. Klingex, B. MacDougall and S. Gottesfeld, Discuss. Faraday Soc. 56 (1973) 210.

13 N.R. de Tacconi, A.J. Calandra and A.J. Arvia, J. Electroanal. Chem., 57 (1974) 267.

14 C.M. Ferro, A.J. Calandra and A.J. Arvia, J. Electroanal. Chem., 53 (1974) 231.

15 B.E. Conway, H. Angerstein-Kozlowska and H.P. Dhar, Electrochim. Acta, 19 (1974) 455. 